Research Article

\title{
Evaluation of drug promotional literature directed to consumers and physicians
}

\author{
Suleiman I. Sharif*, Mohammed M. Hassanein, Mai M. Hassanein
}

Department of Pharmacy

Practice \&

Pharmacotherapeutics, College of Pharmacy, University of Sharjah, United Arab Emirates

Received: 01 February 2016 Accepted: 02 March 2016

*Correspondence to:

Dr. Suleiman I. Sharif,

Email: sharifsi@sharjah.ac.ae

Copyright: (C) the author(s), publisher and licensee Medip Academy. This is an openaccess article distributed under the terms of the Creative Commons Attribution NonCommercial License, which permits unrestricted noncommercial use, distribution, and reproduction in any medium, provided the original work is properly cited.

\begin{abstract}
Background: The present study aims at analysing promotional brochures and direct-to-consumer advertisements using the criteria for ethical medicinal drug promotion compiled by World Health Organization.

Methods: Using World Health Organization criteria for ethical medicinal drug promotion, thirty brochures were evaluated for their fulfilment of the criteria and claims they are making. Also eight Direct to Consumer (DTC) TV advertisements were coded for their claimed indications and the factors used to attract consumers. An overview of what impact does drug promotion has provided through reviewing the published literature.

Results: Brochures and advertisements directed to physicians were found to lack information with regard to generic $(17.2 \%)$, brand $(0 \%)$, indication $(13.8 \%)$, dosage regimen $(27.5 \%)$, safety information $(62 \%)$, references $(10.3 \%)$, manufacture $(3.4 \%)$, safety $(24.1 \%)$, efficacy $(34.5 \%)$, suitability $(20.6 \%)$, pharmacokinetics $(3.4 \%)$ pharmaceutical property $(3.4 \%)$ and extravagant emotional claims (3.4\%). Information lacking in DTC TV advertisements include, risk factors $(62.5 \%)$, alternative treatment $(62.5 \%)$, indications (37.5\%), side effects (75\%), contraindications and sources for more information about the promoted drug $(25 \%)$.

Conclusions: Drug advertisements presented to physicians or directed to consumers did not fully satisfy the WHO criteria and their lack of essential information may lead to medication misuse.
\end{abstract}

Keywords: Evaluation, Drug promotional brochures, DTC, Direct-to-physician, Advertisement

\section{INTRODUCTION}

Drug promotion is defined by World Health Organization (WHO) as all informational and persuasive activities by manufacturers, and distributors to induce /influence the sale and use of medicinal drugs. ${ }^{1}$ The pharmaceutical industry is one of the most strictly regulated industries with regard to advertisement and promotion of its products. The Food and Drug Administration controls all advertising and promotional activities for prescription drugs, including the information given to physicians and pharmacists by pharmaceutical representatives. ${ }^{2}$ Pharmaceutical manufacturers use various promotional tools including, detailing, sampling, medical journal advertising to physicians and pharmacists and direct-toconsumer advertising [DTC]. A principal marketing strategy of pharmaceutical companies is represented by direct-to-physician marketing [DTPM]. This includes visits and presentations by medical representatives, distributing advertising brochures and printed promotional materials and free medication samples. Inoffice presentations by pharmaceutical representatives have been considered a primary promotional tool in pharmaceutical industry. It has a significant impact as many physicians consider them the primary source of information about new medications. ${ }^{3}$ It has been claimed that direct-to-physician promotional activities could influence the physicians' prescribing behaviour without benefiting the patients, as it may lead to irrational prescribing practices. ${ }^{4}$ It has also been stressed that physicians should be aware of the flaws and are urged to evaluate information presented to them and mentioned in the printed promotional materials before accepting them as a valid source for information. ${ }^{4}$ A plethora of studies have shown that drug advertisements have a great impact on the prescribing attitudes of physician without a 
significant improvement in health care delivery to patients. ${ }^{5}$ To keep patient's care a priority and to avoid medication errors, physicians are, ethically and professionally, required to keep their knowledge and skills up to date through the implementation of evidencebased principles. ${ }^{6}$ Pharmaceutical industry their medical representatives to influence the practice of medicine and prescribing through their medical representative by giving gifts, supporting conference attendance, summer holidays offers and free lunches to physicians. ${ }^{7}$

DTC advertisements are any advertisements that are targeted towards the general public. They can be in a magazine, on television, on the radio, on a billboard or any other medium. ${ }^{8}$

DTC advertising is a growing trend in the pharmaceutical industry and it has both positive and negative aspects and impacts on the public. ${ }^{9}$

The increase in DTC advertising of prescription drugs represents a departure from the industry's historical concentration on promotion to physician, hospitals, and other health care organizations. On the other hand, the traditional physician-oriented forms of promotion remain important. Even among those products that employ DTC advertisements, professional promotion continues to command a large share of marketing budget. ${ }^{10}$

Manufactures of advertised drugs claim that such advertisements provide important information for the patient who may benefit from them. ${ }^{11}$ Pharmaceutical companies have campaigned for more flexibility in current regulatory restrictions. Despite the availability of such regulations and controls of drug promotions, information on medicines provided in journals, magazines, and radio or TV are often misleading and lack reliability and have been criticized for their poor quality. ${ }^{12}$

In the present study, we investigated two types of pharmaceutical advertisements the pharmaceutical PDTC and DTPM in terms of fulfilling the regulations of advertising. We also reviewed the most recent published literature regarding drug advertisement in terms of their impact on patients and physicians and assessed a number of pharmaceutical advertisements and brochures using the guidelines of the Food and Drug Administration. ${ }^{2}$

\section{METHODS}

This is an observational study which was conducted in the College of Pharmacy, University of Sharjah -United Arab Emirates (UAE) to evaluate printed promotional materials presented to physicians and prescribers, drug advertisements published in medical periodicals and DTC advertisements presented on TV.

Thirty drug promotional brochures and printed promotional materials were collected randomly from community pharmacies and private clinics in Dubai and Sharjah over the period of September to November 2015. Drug brochures studied were the same as those distributed in other Emirates, thus the sample selected represented the situation in UAE. Supplements and medical devices were excluded because they are out of the scope of this study therefore only fourteen drug brochures were evaluated together with fifteen drug advertisements that were randomly selected from medical periodicals published in the period of June 2010 to May 2015. Descriptive analysis for both the brochures and drug advertisements from medical journals was used based on using "WHO criteria for ethical medicinal drug promotion $1988 .{ }^{13}$

The type of claims and pictorial content presented in the studied brochures and advertisements were also noted. Moreover, eight drug advertisements shown on TV were selected and evaluated for their claims and the documentation of drug-related important information such as the targeted clinical condition, disease risk factors, and drug effectiveness, mechanism of action, adverse effects, and contraindications to use and/or precautions.

In examining the brochures and advertisements, we also reviewed the most recent literature on pharmaceutical advertisements to assess the impact of the pharmaceutical DTC advertisements on the public, the physician-patient relationship and the safe use of medication as well as the effects of DTP advertisements on prescribing behaviour.

WHO criteria for ethical medicinal drug promotion dictate that promotional literature should contain the following information, the names[s] of the active ingredient[s] using either international nonproprietary names [INN] or the approved generic name of the drug, brand name, amount of active ingredient[s] per dose, approved therapeutic uses, dosage form or dosage schedule, safety information including side effects and major adverse drug reactions, precautions, contraindications and warnings, and major drug interactions, name and address of manufacturer or distributor and reference to scientific literature as appropriate. In addition to this information, promotional claims about the medication were examined after being classified under various criteria. These include efficacy to determine if any statements about improved effectiveness of promoted drug as a disease or a patient outcome solely or in comparison with other group of drugs for a similar outcome, safety where the use of the word" Safe" in the promotional text or the mentioning of a reduction in adverse drug reaction and/or drug interaction and/or contraindications has been documented, suitability to examine statements about the comfort of patients, e.g., improved dose, low frequency of dosage, and ease of administration with or without reasons to support such statements, pharmacokinetics of the drug to examine information regarding the properties of the drug as related to its absorption, distribution, biotransformation, 
excretion, half-life and volume of distribution, and finally examining the pharmaceutical properties of the advertised medication such as new dosage formulations, different manufacturing procedures, excipients, storage facilities, etc. We also looked into attractive claims or statements not related to patient outcome, disease outcome or drug e.g. "the first of its kind in the world".

\section{RESULTS}

Figure 1 shows the percentage of brochures and drug advertisements directed to physicians lacking the information that should be present. The percentage of information not mentioned in the evaluated advertisements and brochures ranged from $0 \%$ in the case of brand name to $62 \%$ of safety information.

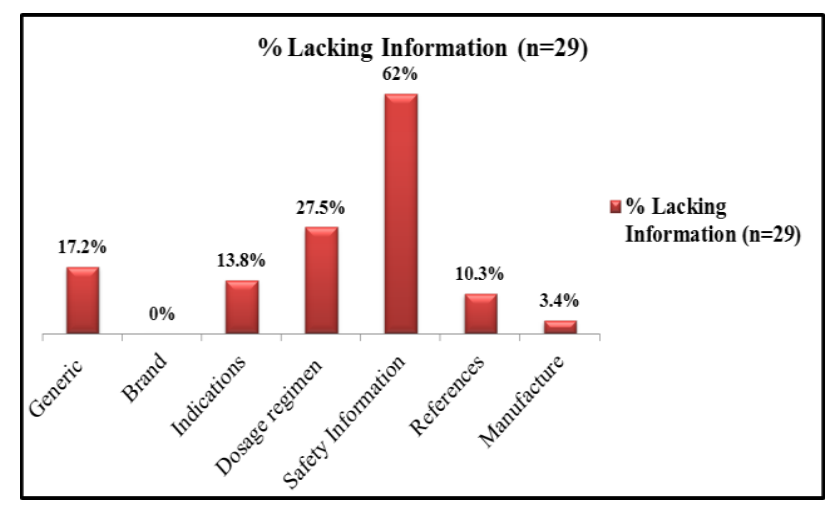

Figure 1: Evaluation of Direct to Physician advertisements. The graph expresses the percentage of brochures and drug advertisements directed to physicians and lacking specific information.

The $\%$ of claims made by manufacturer and present in the brochures with regard to safety, efficacy, suitability, pharmacokinetic property, pharmaceutical property and extravagant emotional claims are shown in Figure 2. The $\%$ presence of such claims ranged from $3.4 \%-34.5 \%$.

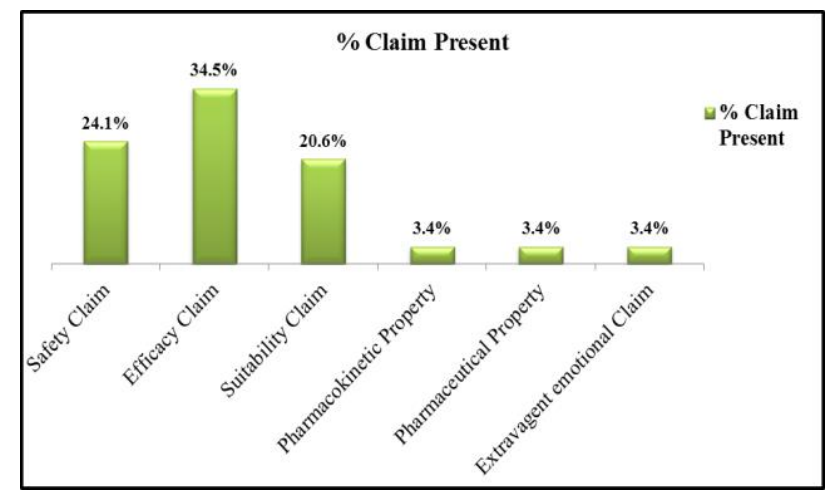

Figure 2: Evaluation of claims in DTP advertisements. The figure shows the percentages of the evaluated claims present in the brochures and advertisements with regard to claims of safety, efficacy, suitability, pharmacokinetic property, pharmaceutical property and extravagant emotional indications.
Concerning drug advertisements shown on TV (Figure 3), information were lacking with regard to disease risk factors $(62.5 \%)$, alternative treatment $(62.5 \%)$, indication $(37.5 \%)$, side effects (75\%), and drug effectiveness $(62.5 \%)$, contraindications to use and/or precautions $(50 \%)$ and reference to other sources $(25 \%)$.

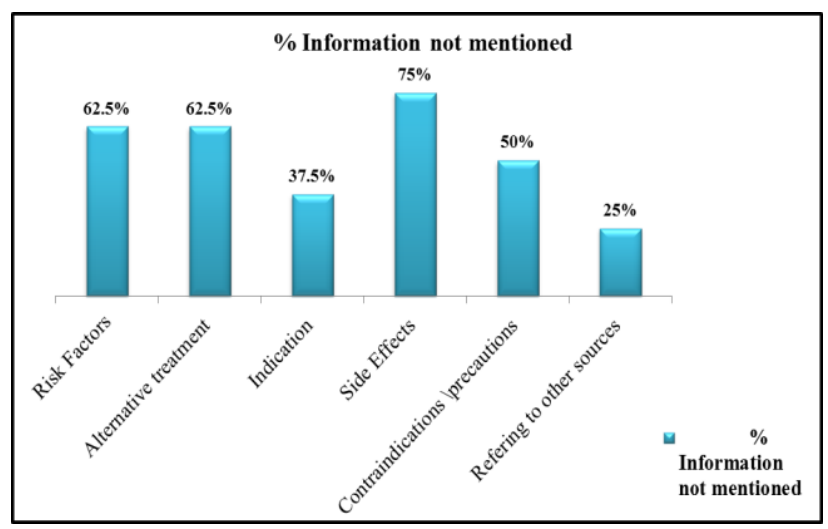

Figure 3: Evaluation of the DTC-TV advertisements. The graph shows the results of advertisements evaluated for the lack of specific information expressed as percentage. Lack of information ranged from $25 \%$ to as high as $\mathbf{7 5 \%}$. The total number of the TV advertisements coded was eight.

Table 1 shows the presence or absence of safety, efficacy and suitability claims and extravagant remarks of certain drugs.

\section{DISCUSSION}

Drug-companies interact with doctors to promote their medical products. Studies have shown that exposure to drug promotion has an effect on prescribing patterns, which may sometimes result in reduced quality of prescribing. ${ }^{4}$ This has been attributed, among other factors, to unintended bias in promotional materials due to the commercial nature of drug promotion. ${ }^{6}$ The selective use of information presented to physicians reduces their ability to make evidence-based decisions and results in suboptimal usage of potentially useful drugs. This has been attributed to confirmation bias resulting from the conflict of interest involved in the investigational studies on drugs that are sponsored by the producing pharmaceutical companies. ${ }^{6}$

Brochures and printed promotional materials distributed by medical and sales representatives are important sources of information that physicians usually rely on to know about medications. Our results clearly show that pharmaceutical companies were more reluctant to present important information regarding the promoted medication as both dosage regimen and safety information were lacking in $27.5 \%$ and $62 \%$ respectively. It was also shown that none of the brochures fulfil the whole criteria including the required information that should be present such as generic name, brand, indication, dosage regimen, 
safety information, manufacture and references for more information about the advertised drug and the different promotional claims about the medication. However, the examined printed material documented claims regarding safety [24\%] and efficacy [34\%], but information about side effects, contraindications and/ or precautions were missing.

Table 1: Examples on the presence or absence of safety, efficacy and suitability claims and extravagant remarks of certain drugs.

\begin{tabular}{|c|c|c|c|c|}
\hline Drug & Safety Claim & Efficacy Claim & Suitability Claim & Remarks \\
\hline Cetirizine & Not present & Not present & Not present & \\
\hline Clopidogrel & Not present & Not present & Not present & \\
\hline Bisoprolol & Not present & $\begin{array}{l}\text { Present" Heart First } \\
\text { choice" }\end{array}$ & Not Present & \\
\hline Topiramate & Present & Not present & Not present & \\
\hline Perindopril & Not present & Not present & Not present & \\
\hline Rosuvastatin & $\begin{array}{l}\text { Present " It has better } \\
\text { safety profile compared } \\
\text { with other statins" }\end{array}$ & $\begin{array}{l}\text { Present -compared } \\
\text { with other Statins }\end{array}$ & Not present & $\begin{array}{l}\text { It is the most effective. } \\
\text { Better safety than other } \\
\text { statins }\end{array}$ \\
\hline $\begin{array}{l}\text { Irbesartan/ } \\
\text { Hydrochlorothiazide }\end{array}$ & Present & Not present & Not present & \\
\hline Simvastatin & Not present & Not present & Not present & \\
\hline Atorvastatin & Not present & Not present & Not present & $\begin{array}{l}\text { It is superior to other } \\
\text { treatments }\end{array}$ \\
\hline $\begin{array}{l}\text { Glyburide and } \\
\text { Metformin }\end{array}$ & Not present & $\begin{array}{l}\text { Present" Higher } \\
\text { efficacy than other } \\
\text { combined therapies" }\end{array}$ & $\begin{array}{l}\text { Present } \\
\text { "Excellent } \\
\text { tolerability " }\end{array}$ & $\begin{array}{l}\text { Improves patient } \\
\text { compliance }\end{array}$ \\
\hline Rabeprazole & Not Present & $\begin{array}{l}\text { Present " Not All } \\
\text { PPI's are the same" }\end{array}$ & $\begin{array}{l}\text { Present " Your } \\
\text { consistently fast } \\
\text { working PPI's }\end{array}$ & "Acts in an hour" \\
\hline Ibuprofen & $\begin{array}{l}\text { Present " Important } \\
\text { safety information and } \\
\text { warnings " }\end{array}$ & Not Present & Not Present & \\
\hline Fenofibrate & Not Present & Not Present & Present & $\begin{array}{l}\text { There is more to it than } \\
\text { you think" }\end{array}$ \\
\hline Candesartan & Not present & $\begin{array}{l}\text { Present "Proven } \\
\text { protection from } \\
\text { hypertension to heart } \\
\text { failure" }\end{array}$ & Not Present & $\begin{array}{l}\text { "Proven protection from } \\
\text { Hypertension to heart } \\
\text { failure" }\end{array}$ \\
\hline
\end{tabular}

It has been noted that the attitudes of physicians towards detailing and pharmaceutical sales representatives were mostly negative as $48 \%, 44 \%$ and $28 \%$ of physicians were not satisfied with detailing, did not believe in the accuracy and objectives of the information and denied influence of medical representatives on formulary decisions respectively. ${ }^{14}$ The same study also revealed that the major goal of sales representatives was to promote their drugs with only little intention to educate physicians. The argument that DTC promotions are educational for the public about medical conditions and their treatments depends on the quality of drug information available to consumers through advertising. Consumers being non-medically oriented may even become confused and have wrong perception of the effectiveness and safety of the drug despite the accurate information in the DTC. ${ }^{15}$
In the present study more than one third of the advertisements did not mention the indication and about two thirds did not mention some or all of the risk factors of the disease for which the drug is given.

Many new drugs with less understood safety profiles may offer few advantages over pre-existent. ${ }^{17}$ In the present study, we observed that the majority of the studied TV advertisements did not mention side effects and half of them did not mention any contraindications and/or precautions. This could be attributed to the fact that DTC advertisements tend to overemphasize the positive aspects of a drug and provide only little importance to the negative or unknown aspects. We noticed that side effects of the promoted drug either listed last or not mentioned at all and only one quarter of the advertisements referred the 
consumer to other sources for more complete information about the drug.

It has been shown that most of the information on the internet is not accurate and of poor quality as they fail to have the reliability that ensures the patient's safety. ${ }^{18}$ It has also been reported that online pharmacies often lacked important information about contra-indications for medications available on their sites. ${ }^{19}$ These add to the many obvious problems encountered with ordering drugs online such as counterfeit drugs.

The various measures drug manufactures use to attract consumers to the promoted drugs has a great impact on the physician- patient relationship. ${ }^{20}$ It is well known that some patients are usually in the habit of directly asking their physician to prescribe for them a particular drug and it is likely that highly promoted medications will be on top of the list of patient's requests. This is true especially with drugs that have been exposed to through selfmedication or self-diagnosing of their conditions. Despite its several advantages, self- medication may on the other hand result in serious adverse effects, misdiagnosis and mistreatment, emergence of resistant pathogens in case of self-medication with antibiotics and drug abuse and dependence in some cases. $^{21}$

Previous studies have shown that DTC advertisements do influence consumer and physician behavior and have clearly demonstrated that such advertisements motivate discussions between patients and physicians and generate requests for prescriptions, implying a potentially significant impact on the physician-patient relationship. ${ }^{22}$ The risk of adverse drug reaction increases when patient ask the physician to switch them from an already wellstudied drug regarding its safety profile to a totally new drug which might still lack safety studies. However, it has also been argued that DTC advertisements makes consumers better informed and more sophisticated. ${ }^{23}$ Consumers are enabled, through DTC advertisements, to better understand the market for drugs and the therapeutic options available to them. This view is also shared by others, who argue that consumers can engage in more equitable relationships with health care providers and become partners in their own health care as a result of DTC advertisements. ${ }^{24}$

Drug advertisements have a great impact on physicians as prescribers, pharmacists as dispensers and patients as consumers thus the content of all drug promotional materials should be subjected to strict regulations and critical revision before being published. Pharmacists also should play an important role in ensuring the accuracy and reliability of information mentioned in these promotional materials. Physicians also should be more cautious when depending on the information present to make a decision about their patient's therapeutic options. A significant role can also be played by the pharmacist who should be as an expert on drugs the first line defence to critically revise advertisements, report their inaccuracy or falsified claims to health authorities. The pharmacist should also provide patients with the appropriate information and instructions on the rational use of drugs.

\section{CONCLUSION}

In conclusion, drug advertisements and promotions can have a great impact on consumers' health. Information provided should be reliable and accurate as they can influence the treatment decisions of physicians and consumers. However, pharmaceutical industries do not strictly follow the World Health Organization [WHO] guidelines while promoting their products. Little information is, sometimes, provided to physicians to make them take the right decision regarding their patient therapeutic options, and also consumers are provided with little information about the safety of the drug products.

Health authorities should apply more strict regulations and controls on advertisements either presented directly to consumer or to the physician. Advertisements in magazines and periodicals should not be published if they do not include all the essential information needed for the physician to make a judicious decision about the product.

Funding: No funding sources

Conflict of interest: None declared

Ethical approval: The study was approved by the Institutional Ethics Committee

\section{REFERENCES}

1. Bansal RK, Das S. Unethical relationship between doctors and drugs companies. J Ind Acad Foren Med. 2005;27(1):40-42.

2. Rongey CM. Advertising and the pharmaceutical industry. Encyclopedia of Drugs, Alcohol, and Addictive Behavior. 2011. Encyclopedia.com: http://www.encyclopedia.com/doc/1G2-

3403100029.html. Accessed 31 October 2015)

3. Cardarelli R, Licciardone JC, Taylor L. A crosssectional evidence-based review of pharmaceutical promotional marketing brochures and their underlying studies: Is what they tell us important and true. BMC Family Practice. 2005;7(13).

4. Mali SN, Sujata D, Bachewar NP. Evaluation of rationality of promotional drug literature using world health organization guidelines. Ind $\mathbf{J}$ Pharmacol. 2010;42(5):267-272.

5. Sharif SI, Abduelkarem AR. Analysis of written pharmaceutical advertisements in Dubai \& Sharjah. Saudi Pharmaceu J. 2008;16:252-7.

6. Buckley J. Pharmaceutical marketing - time for change. Electronic Journal of Business Ethics and Organization Studies. 2004;9(2):4-11.

7. Higgins SP. Drug representatives: Giving you lunch or stealing your soul. Dermatology Online Journal. 2007; 13(4):5. 
8. Shaw A. Direct-to-consumer advertising of pharmaceuticals. http://www.csa.com/discovery guides/ direct/review.php. 2008. Accessed 12 November 2011.

9. Kaiser Family Foundation. Impact of direct-toconsumer advertising on prescription drug spending No. 6084). Washington, DC: Kaiser Family Foundation. http://www.kff.org/rxdrugs/ loader.cfm?url=/commonspot/security/getfile.cfm\& PageID=14378/ Accessed 17 November 2011 .

10. Rosenthal MB, Berndt ER, Donohue JM, Epstein AM, Frank RG. Demand effects of recent changes in prescription drug promotion. In D. M. Cutler, \& A. M. Garber (Eds.), Frontiers in health policy research (6th ed., pp. 1-26) MIT Press. 2003.

11. Pauline N, Herxheimer A, Lexchin J, Mansfield P. What we know, what we have yet to learn - reviews of materials No. EDM Research Series No. 032). World Health Organization and Health Action International. 2004. http://www.drugpromo.info/, Accessed 05 December 2011.

12. Villanueva P, Peiró S, Librero J, Pereiró I. Accuracy of pharmaceutical advertisements in medical journals. The Lancet. 2003;361(9351):27-32.

13. WHO. Ethical criteria for medicinal drug promotion. (Essential Drugs Monitor No. 017). Geneva: World Health Organization. 1988. Accessed 04 December 2015

14. Manchanda P, Honka E. The effects and role of direct-to-physician marketing in the pharmaceutical industry: An integrative review. Yale J Health Policy Law Ethics. 2005;5(2):785-822.

15. Cohen, EP. Direct-to the-public advertisement of prescription drugs. N Eng J Med. 1988;318(6):3736.
16. Kessler DA, Pines WL. The federal regulation of prescription drug advertising and promotion. JAMA. 1990;264(18):2409-15.

17. Bloom BS, Iannacone RC. Internet availability of prescription pharmaceuticals to the public. Ann Int Med. 1999;131(11):830-3.

18. Smith R. Medical journals and pharmaceutical companies: Uneasy bedfellows. $\mathrm{Br}$ Med J. 2003;326(7400):1202-5.

19. Robinson AR, Hohmann KB, Rifkin JI, Topp D, Gilroy CM, Pickard JA, et al. Direct-to-consumer pharmaceutical advertising. physician and public opinion and potential effects on the physicianpatient relationship . Arch Intern Med. 2004;164(4):427-32.

20. Bloom BS, Iannacone RC. Internet availability of prescription pharmaceuticals to the public. Ann Int Med. 1999;131(11):830-3.

21. Hughes CM, McElnay JC. Fleming GF: Benefits and risks of self medication. Drug Saf. 2001;24:1027-37.

22. Donohue JM, Cevasco M, Rosenthal MB. A decade of direct-to-consumer advertising of prescription drugs. N Engl J Med. 2007;357(7):673-81.

23. Flynn LT. Does direct to consumer advertising of prescription drugs benefit the public's health? - yes American Council on Science and Health.1999;11(4).

24. Calfee J. Public policy issues in direct-to-consumer advertising of prescription drugs. Journal Public Policy and Marketing. 2002;21(2):174-9

Cite this article as: Sharif SI, Hassanein MM, Hassanein MM. Evaluation of drug promotional literature directed to consumers and physicians. Int $\mathbf{J}$ Basic Clin Pharmacol 2016;5:478-83. 